МРНТИ06.61.33

УДК 331.5

https://doi.org/10.51579/1563-2415.2021-1.27

\title{
ПРОСТРАНСТВЕННАЯ МОБИЛЬНОСТЬ РАБОЧЕЙ СИЛЫ, ОРИЕНТИРОВАННАЯ НА ВОЗМОЖНОСТИ РАЗВИТИЯ ПРЕДПРИНИМАТЕЛЬСТВА \\ ${ }^{*}$ С.В.Беспалый, Л. И. Каиук, А.Р. Солтангазинов \\ "Инноваџионный Евразийский университет, г. Павлодар, Казахстан \\ e-mail: sergeybesp@mail.ru
}

Аннотация.Литература по региональному предпринимательству имеет тенденцию пренебрегать межрегиональными потоками человеческого капитала, и, тем не менее, пространственная мобильность предоставляет зарождающимся предпринимателям знания и сети в разных местах для использования предпринимательских возможностей. Целью проведенного исследования являлось установление взаимосвязи между мобильностью и предпринимательством. Изучено, с помощью чего многопрофильный опыт и нелокальные знания обеспечивают мигрантов стремлением к предпринимательству, основанному на возможностях. Показана связь между региональной средой и предпринимательскими мотивами, основанными на возможностях, для людей с опытом пространственной мобильности и без него. Приведен анализ данных обследования динамики рабочей сильл, в котором сравниваются характеристики и движущие силь предпринимательских мотивов мигрантов и местных жителей. Проведен опрос, который свидетельствует о более высокой распространенности предпринимательской деятельности, основанной на возможностях, среди предпринимателей-мигрантов по сравнению с их местныли коллегами.

На основе проведенного анализа и опроса установлено, что опыт пространственной мобильности значительно повышает вероятность вступления в бизнес, основанный на возможностях. Региональная среда оказывает влияние на предпринимательские мотивы мигрантов и не мигрантов, но по-разному. Местные предприниматели в большей степени подвержень влиянию эндогенного характера фирмы, в то время как предприниматели-мигранты начинают бизнес, основанный как на местных потребностях, так и на внешней связи с более обширными рыночными зонами.

Ключевые слова: мигранты; пространственная мобильность; предпринимательские мотивы; предпринимательство, основанное на возможностях; предпринимательство, основанное на необходимости.

Основные положения. Мигранты являются носителями знаний и создателями сетей, а их опыт мобильности обеспечивает способность городов и регионов внедрять в многопозиционные и мультискалярные процессы накопленные знания.

Анализ предпринимательской деятельности, основанной на возможностях, среди предпринимателеймигрантов показал, что опыт мобильности перевешивает локальную личную сеть с точки зрения повышения вероятности начала бизнеса, основанного на возможностях. Вклад этого исследования заключается в демонстрации потенциально отличительного механизма, действующего через пространственную мобильность предпринимательских агентов, лежащих в основе процессов регионального предпринимательства.

Введение. Предпринимательство, основанное на возможностях, определяется как предпринимательские решения, мотивированные восприятием и использованием инновационных бизнес-идей. Это понятие было впервые введено в опросе GlobalEntrepreneurshipMonitor, в отличие от предприимчивости, обусловленной необходимостью, когда люди вынуждены начинать собственный бизнес из-за безработицы или неудовлетворенности работой. Предпринимательство, основанное на возможностях, в отличие от предпринимательства, основанного на необходимости, положительно влияет на инновации и технологический прогресс, таким образом, являясь формой производительного предпринимательства.

Статья построена следующим образом. Рассматривается литература, относящаяся к взаимосвязи между пространственной мобильностью и предпринимательством, основанным на возможностях, и выдвигается гипотеза о разной взаимосвязи между региональной средой и предпринимательскими мотивами среди людей с опытом пространственной мобильности и без него. Статья затрагивает два исследовательских вопроса, касающихся предпринимательской деятельности внутренних мигрантов: во-первых, как опыт, приобретенный мигрантами ранее,способствует формированию предпринимательских мотивов, основанных на возможностях? Во-вторых, в какой степени и каким образом региональная среда взаимодействует с мигрантами, имеющими знания, для формирования ориентированного на возможности предпринимательства? Далее приводятся данные опроса, по влиянию различных региональных факторов, связанных с предпринимательскими мотивами мигрантов и не мигрантов. В заключение представлены результаты в отношении пространственной мобильности и предпринимательских мотивов.

Методы. В статье, приведен анализ международных исследований, а также обзор казахстанских источников, посвященных эмпирическим исследованиям пространственной мобильности и ориентированного 


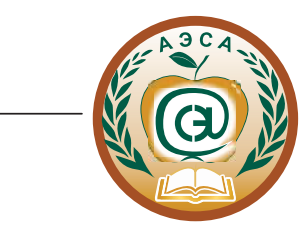

на возможности предпринимательства на разных территориях. В ходе исследования был проведен опрос, касающийся оценки пространственной мобильности, влияющей на предпринимательские возможности.Данные опроса показали высокой уровень распространенности предпринимательской деятельности, основанной на возможностях, среди предпринимателей-мигрантов по сравнению с их местными коллегами.Кроме того, что опыт пространственной мобильности значительно повышает вероятность вступления в бизнес, основанный на возможностях.

Собранный эмпирический материал и его анализ позволил определить региональные пространственные факторы и их влияние на мобильность и ориентированное на возможности предпринимательство в различных территориях Республики Казахстан.

Результаты и обсуждение. В последнее десятилетие наблюдается рост исследований по региональному предпринимательству. Тем не менее, теории в области региональных исследований предпринимательства переоценивают эндогенные процессы развития предпринимательства и инноваций[1]. Это правда, что предпринимательские возможности сконцентрированы в определенных местах, которые обладают хорошо функционирующими предпринимательскими экосистемами, но также сильно зависят от способности людей использовать эти возможности[2]. Тем не менее, вопрос о том, кто начинает бизнес, основанный на возможностях, все еще привлекает ограниченное внимание исследователей. Исследование о предпринимателях в Силиконовой долине впервые выявило экономический вклад мигрантов как начинающих предпринимателей в экономику. Действительно, мигранты все чаще рассматриваются в качестве источника оживления региональной экономики[3]. С этой точки зрения межрегиональная мобильность человеческого капитала и разнородные знания о местоположении играют ключевую, но недостаточно изученную роль в развитии предпринимательства.

В качестве отправной точки концептуальной ясности объект исследования этой статьи ориентирован на внутренних мигрантов в Казахстане по двум причинам. Во-первых, число внутренних мигрантов в мире составляет около 740 миллионов человек, что более чем в три раза превышает число международных мигрантов. По данным Агентства по стратегическому планированию и реформам Республики Казахстан, Бюро национальной статистики в 2019 году внутренние мигранты в Казахстане составляют более 1 млн 115,7 тыс. чел. [4]. Таким образом, внутренний мигрант заслуживает исследовательского внимания не только из-за его огромных масштабов, но и из-за его более широкого значения для человеческого потенциала в поиске экономических возможностей и мобильности [5]. Во-вторых, внутренняя миграция служит подходящим параметром для изучения роли пространственной мобильности на региональном уровне, а не на уровне страны. Несмотря на давний упор экономических географов на международную миграцию как более важный способ передачи знаний, ученые, в исследованиях начали замечать, что международные мигранты часто имеют пространственную биографию, как и внутренние мигранты. Это косвенно указывает на сложные процессы мобильности, в которых локальные знания накапливаются постепенно. Как и в случае международной миграции, предприниматели-иммигранты должны преодолеть как региональные (например, из Павлодара в НурСултан), так и страновые (например, из Казахстана в Россию) барьеры в институциональной, культурной и социальной среде. Сосредоточение внимания на внутренних мигрантах позволяет нам исследовать, является ли межрегиональная неоднородность знаний ценным активом для высококачественной предпринимательской деятельности.

Роль внутренних мигрантов в продвижении регионального предпринимательства посредством пространственной мобильности и нелокальных знаний стала очевидной в ряде недавних исследований[6, 7,8$]$. Мартынович в своем исследовании сравнил информационные данные о предпринимателях местных и переехавших, изучив относительную важность нелокальных знаний в сравнении с местной вовлеченностью в предпринимательство [6].

Опьт пространственной мобильности, ориентированный на возможности предпринимательства. Предпринимательство, основанное на возможностях, рассматривается как форма продуктивного предпринимательства, в которой предпринимательские мотивы двигаются стремлением людей к достижениям с восприятием рыночных возможностей и эксплуатацией инновационных идей. Напротив, предпринимательская деятельность, обусловленная необходимостью, продвигается личными потребностями в выживании, такими как непривлекательные или недоступные возможности трудоустройства. В целом, предпринимательская деятельность, основанная на возможностях, создает больше рабочих мест и доходов, чем деятельность, обусловленная необходимостью.

Исследования инноваций уже доказали, что неоднородные источники знаний могут вызывать новые инновации.До недавнего времени пространственная мобильность ассоциировалась с предпринимательскими навыками и инновациями. Пространственная мобильность мигрантов определяется в этой статье как личный опыт проживания в более чем одном месте. Ученые, систематически представляют важность нелокальных знаний в создании нового регионального пути во всех типах региональных инновационных систем, хотя они неявно подчеркивают больше глобально передаваемых знаний [9]. Другие исследования, однако, основаны на 
межрегиональной мобильности внутри страны. Исследователи делают акцент либо на местной вовлеченности, либо на международной миграции талантов, эмпирически подтверждая тот факт, что внутренние перемещения в пределах национальных границ увеличивает вероятность вхождения в предпринимательство [8]. Что касается стимулирования предпринимательства, основанного на возможностях, то есть, два способа. Вопервых, опыт жизни и работы в более чем одном месте дает мигрантам знания из разных мест. Во-вторых, мигранты обладают преимуществами обладания знаниями транслокальной сети по сравнению с немобильными местными жителями. Хотя, мигранты могут столкнуться с трудностями при использовании предпринимательского опыта и сетей в других регионах и сельских территориях проживания. Но тем не менее, предприниматели-мигранты могут компенсировать потерю местных социальных сетей за счет знаний накопленных ранее.

Нелокальные знания мигрантов будут положительно влиять на формирование предпринимательства, основанного на возможностях.

Предприниматели-мигранты и взаимодействие со структурой возможностей территорий. Предпринимательские процессы в значительной степени зависят от институционально ограниченных процессов сопоставления между мотивированными предпринимательскими талантами и потенциальными предпринимательскими возможностями. Существует множество факторов на уровне региона, поощряющих или препятствующих развитие предпринимательства. Можно утверждать, что мигранты и немигранты сталкиваются с различными региональными структурами возможностей при создании фирм и предприятий, так как они имеют разный доступ к ресурсам в различных пространственных масштабах и в разной степени локальной вовлеченности.В этом отношении местные жители имеют больше возможностей ориентироваться и получать доступ к потенциальному человеческому капиталу для поддержки начальной фазы. Напротив, мигранты могли бы обратиться к внешней сети и базе знаний, чтобы искать возможности для предпринимательства и поддержку.

Начнем с того, что количество возможностей определяется как ключевое измерение региональной структуры, которая влияет на формирование предпринимательства, основанного на возможностях. Со стороны спроса, более высокий уровень доходов жителей тех или иных территорий может поддержать использование быстрорастущих предпринимательских возможностей. Если сравнить качество предпринимательской деятельности в разных регионах с низким доходом и в регионах с высоким доходом, можно сделать вывод, что предприниматели с мотивированными потребностями имеют более высокую вероятность быть успешными и продуктивными в регионах с низким доходом. С одной стороны, если люди хотят только начать бизнес, обусловленный необходимостью, у них нет стимулов для перехода в регионы с более высокими доходами. С другой стороны, более богатые территории, способные развивать и поддерживать рост новых малых предприятий, привлекают потенциальных предпринимателей для открытия бизнеса, основанного на возможностях.

С точки зрения предложения, теория предпринимательства, распространяющая знания, впервые предложенная немецким экономистом Аудретшем, рассматривала региональные знания и плотность организаций, производящих знания, как источник предпринимательской деятельности[10]. Как для мигрантов, так и для местных жителей количество возможностей, существующих в окружающей среде, побуждает их вступать в бизнес, основанный на возможностях, а не на необходимость.

Вероятность мигрантов начать бизнес, основанный на возможностях, будет успешным в регионах с высоким доходом.

Далее разберем взаимосвязи между предпринимательством, основанным на возможностях, и экосистемой регионального предпринимательства, в первую очередь касающейся окружения фирмы и наличия талантов, которое было сформулировано на основе дифференцированного взаимодействия мигрантов и местных жителей с экосистемой.

Вероятность того, что местные жители начнут бизнес, основанный на возможностях, положительно связана с окружением фирмы в регионе.

Вероятность как мигрантов, так и местных жителей начать бизнес, основанный на возможностях, положительно связана с наличием молодых талантов в регионе.

Вероятность того, что мигрант начнет основанный на возможностях бизнес, напрямую связана с доступом региона на внутренний рынок.

Вероятность запуска мигрантом бизнеса, основанного на возможностях, положительно связана с региональным притоком иностранных инвестиций.

Ключевым фактором, который необходимо учитывать при оценки, является история миграции, которая должна включать две переменные для интерпретации влияния пространственной мобильности на предпринимательские мотивы. Следует отметить, что исследование фокусируется на мобильности и опыте, а не просто на обладании миграционным статусом. Следовательно, первая переменная состоит в том, чтобы идентифицировать опыт пространственной мобильности, что позволяет оценить знания о местоположении и адап- 


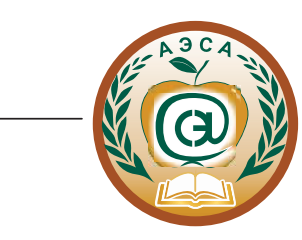

тироваться к новой региональной среде. Необходимо также учитывать количество миграций внутри Казахстана для измерения степени индивидуальной пространственной мобильности и степени, в которой люди обладают знаниями об определенных территориях.

Данные переменные также должны включать факторы на индивидуальном уровне. Сначала рассматривается демографическая характеристика людей, в том числе пол, возраст и уровень образования. Что еще более важно, необходимо включать встроенность в локальные социальные сети, измеряемую количеством надежных связей, друзей в регионе, которые могут повлиять на создание бизнеса.

Существуют несколько переменных, используемых для отражения региональной предпринимательской среды. Все региональные переменные могут быть рассчитаны как среднее значение за последние 3 года с тех пор, как отдельные лица стали самозанятыми или работодателями. Первый - это ВВП на душу населения, используемый для определения уровня доходов в регионе, который влияет на развитие предпринимательских возможностей со стороны спроса. Второй показатель измеряется количеством студентов в высших учебных заведениях. Третий показатель - транспортная доступность, чтобы измерить размер потенциалов внутреннего рынка. Транспортные исследования показывают, что объем грузоперевозок отражает размер местного рынка. Таким образом, объем грузопотока может использоваться для представления степени рынка и доступа к удаленным рынкам.

В рамках исследования был проведен опрос внутренних мигрантов и местных жителей территорий Павлодарской области (мигрантов - 2723, местных жителей -5825). Рассмотрим описательный анализ статуса занятости и характеристик предпринимателей. В таблице 1 сравнивая статус занятости между мигрантом и немигрантоми не обнаруживается различий между этими двумя группами с точки зрения статуса занятости. Как для мигрантов, так и для немигрантов, около четверти населения в настоящее время или ранее занималось предпринимательской деятельностью.

Таблий 1

Занятость мигрантов и немигрантов, в процентах

\begin{tabular}{|l|c|c|}
\hline \multicolumn{1}{|c|}{ Статус занятости } & $\begin{array}{c}\text { Мигран- } \\
\text { ты }\end{array}$ & $\begin{array}{c}\text { Немигрирующие } \\
\text { (местные жители) }\end{array}$ \\
\hline Работодатели & 11 & 9 \\
\hline В настоящее время работающий не по найму & 14 & 14 \\
\hline Действующие сотрудники с опытом предпринимательской деятельности & 3 & 3 \\
\hline Нынешние сотрудники без предпринимательского опыта & 72 & 74 \\
\hline Итого & 100 & 100 \\
\hline
\end{tabular}

Тем не менее, дальнейший анализ социально-демографических показателей показывает, что предприниматели-мигранты более образованны, чем предприниматели, не являющиеся мигрантами.

В таблице 2 показаны предпринимательские мотивы предпринимателей-мигрантов и немигрантов.

Таблица 2

Причины стать предпринимателями, сравнение между мигрантами и не мигрантами предпринимателями, в прочентах

\begin{tabular}{|c|c|c|}
\hline Показатели & $\begin{array}{l}\text { Предприниматель- } \\
\text { мигрант }\end{array}$ & $\begin{array}{c}\text { Предприниматель } \\
\text { не мигрант }\end{array}$ \\
\hline Нет возможности трудоустройства & 40 & 49 \\
\hline $\begin{array}{l}\text { Нет возможности трудоустройства, но воспользоваться хоро- } \\
\text { шей предпринимательской возможностью }\end{array}$ & 14 & 13 \\
\hline $\begin{array}{l}\text { Иметь возможность трудоустройства, но воспользоваться хо- } \\
\text { рошей предпринимательской возможностью }\end{array}$ & 38 & 33 \\
\hline $\begin{array}{l}\text { Возможность трудоустройства хороша, но предприниматель- } \\
\text { ская возможность еще лучше }\end{array}$ & 8 & 5 \\
\hline Итого & 100 & 100 \\
\hline
\end{tabular}

Интересно, что предприниматели-мигранты начинают свой бизнес, который в большей степени стимулируется использованием предпринимательских возможностей. Таблица 2 показывает, что 46\% предпринимателей-мигрантов, по сравнению только с $38 \%$ коллегами-немигрантами, становятся работающими не по найму или работодателями, несмотря на достойные предложения о работе. Стало очевидным, что способность мигрантов к пространственной мобильности и многоплановым знаниям представляет собой преимуще- 
ство для предпринимательства. Согласно данным, 86\% предпринимателей-мигрантов имеют трудовой стаж в более чем одном населенном пункте, прежде чем начать работу вместе миграции.

Заключение. В ходе исследования, было выявлено:

1. Мигранты являются носителями знаний и создателями сетей, а их опыт мобильности обеспечивает способность территорий и регионов внедрять процессы накопления знаний.

2. Предпринимательская деятельность, основанная на возможностях, среди предпринимателеймигрантов может успешно реализовываться. Опыт мобильности перевешивает локальную личную сеть с точки зрения повышения вероятности начала бизнеса, основанного на возможностях. В результате, ориентированная на мигрантов предпринимательская политика должна быть признана в экономике знаний, нацеленной на продвижение производительного предпринимательства.

3. Местные предприниматели в большей степени подвержены влиянию эндогенного характера окружения фирмы в той или иной территории, в то время как предприниматели-мигранты начинают бизнес, движимые как влиянием уровня местного дохода, так и внешней связью с более обширными рынками.

4. Региональная связь с внешним рынком выгодна для привлечения и запуска бизнеса мигрантом, внедрения новых знаний и увеличения размера местных стартапов. Следовательно, растущая предпринимательская экосистема, в которой доминируют МСП, побуждает местных жителейначинать бизнес, основанный на возможностях. Также, если власти территорий хотят извлечь максимальную выгоду из инвестиций в создание предпринимательской экосистемы, им следует также приложить усилия для ассимиляции мигрантов и повышения их вовлеченности.

5. В дальнейшем, возможно исследовать, как региональная среда влияет на мигрантов и немигрантов, а также перечень стимулирующих факторов в различных территориях.

\section{Список использованной литературы:}

1. Искакова, М.С., Алшембаева, Л.Т. Государственное управление развитием малого предпринимательства. /М.С. Искакова, Л.Т. Алшембаева// Проблемы Агрорынка. -2019.-№4.-С. 185-191.

2. Беспалый, С.В.Влияние пространственных факторов на развитие пригородных сельских территорий Павлодарской области Республики Казахстан/ С.В. Беспалый// Проблемы Агрорынка. -2020.-№1.-С. 165171.

3. Рыбаковский, Л.Л. Миграция населения: учеб. пособие для вузов /Л.Л.Рыбаковский. - Москва: Юрайт, 2019. -480 с.

4. Агентства по стратегическому планированию и реформам Республики Казахстан, Бюро национальной статистики. - (https://stat.gov.kz/).

5. Попова, И.В. Миграция в современном мире: тенденции и вызовы XXI столетия: монография. Новосибирск: СибАК, 2016. - 100 с.

6. Martynovich, M. The role of local embeddedness and non-local knowledge in entrepreneurial activity. Small Business Economics. - 2017. - № 49(4), - P. 741-762.

7. Frederiksen, L., Wennberg, K., Balachandran, C. Mobility and entrepreneurship: Evaluating the scope of knowledge-based theories of entrepreneurship. Entrepreneurship Theory and Practice. - 2016. - № 40(2), - pp. 359380.

8. Huggins, R., Thompson, P. Culture, entrepreneurship and uneven development: A spatial analysis. Entrepreneurship \& Regional Development. - 2015. - № 26(9-10), - pp. 726-752.

9. Tirppl, M., Grillitsch, M., Isaksen, A. Exogenous sources of regional industrial change: Attraction and absorption of non-local knowledge for new path development. ProgressinHumanGeography. - 2018. - №42(5), - pp. 687-705.

10. Audretsch, D. B., Belitski, M. Entrepreneurial ecosystems in cities: Establishing the framework. Journal of Technology Transfer. - 2017. - № 42(5), - pp.1030-1051.

References

1. Iskakova, M.S., Alshembaeva, L.T. Gosudarstvennoe upravlenie razvitiem malogo predprinimatel'stva (State management of small business development), ProblemyAgrorynka, 2019, No4, pp. 185-191.

2. Bespalyy, S.V. Vliyanie prostranstvennyh faktorov na razvitie prigorodnyh sel'skih territorij Pavlodarskoj oblasti Respubliki Kazahstan (The influence of spatial factors on the development of suburban rural areas of the Pavlodar region of the Republic of Kazakhstan), ProblemyAgrorynka, 2020, No1, pp. 165-171.

3. Rybakovskij, L.L. Migraciya naseleniya: ucheb. Posobie dly avuzov (Migration of the population: textbook. textbook for universities), YUrajt, 2019, 480 p.

4. Agentstvo po strategicheskomu planirovaniyu i reformam Respubliki Kazahstan, Byuro nacional'noj statistiki. - (https://stat.gov.kz/).

5. Popova, I.V. Migraciya v sovremennom mire: tendencii i vyzovy XXI stoletiya: monografiya (Migration in the modern world: trends and challenges of the XXI century: monograph), Novosibirsk:SibAK, 2016, 100 p. 
6. Martynovich, M. The role of local embeddedness and non-local knowledge in entrepreneurial activity,Small Business Economics, 2017, No 49(4),pp. 741-762.

7. Frederiksen, L., Wennberg, K., Balachandran, C. Mobility and entrepreneurship: Evaluating the scope of knowledge-based theories of entrepreneurship, Entrepreneurship Theory and Practice, 2016, No 40(2), pp. 359-380.

8. Huggins, R., Thompson, P. Culture, entrepreneurship and uneven development: A spatial analysis, Entrepreneurship \& Regional Development, 2015,No 26(9-10), pp. 726-752.

9. Tirppl, M., Grillitsch, M., Isaksen, A. Exogenous sources of regional industrial change: Attraction and absorption of non-local knowledge for new path development. ProgressinHumanGeography, 2018, No42(5), pp. 687705 .

10. Audretsch, D. B., Belitski, M. Entrepreneurial ecosystems in cities: Establishing the framework,Journal of Technology Transfer, 2017, No 42(5),pp.1030-1051.

\section{КӘСІПКЕРЛІКТІ ДАМЫТУ МУМКІНДІГІНЕ БАҒЫТТАЛҒАН ЖҰМЫС КУШІНІН КЕНІСТІК ҰТКЫРЛЫҒЫ}

${ }^{*}$ С.В.Беспалый, Л. И. Кашук,А.Р. Солтангазинов

Инноваџияльққ Еуразия университеті, Павлодар к̧., Қазақ̆стан

e-mail:sergeybesp@mail.ru

Түйін. Аймақтық кәсіпкерлік тураль ддебиеттер адам капитальның аймақаралық авындарын елемеуге тырысады, алайда кенуістіктік ұтқырлық дамып келе жатқан кәсіпкерлерге кәсіпкерлік мүмкіндіктерді пайдалану ушін әртүрлі жерлерде білім мен желілерге мүмкіндік береді. Жүргізілген зерттеудің мақсаты ұтқырлық пен кәсіпкерлік арасындавы байланысты орнату болды. Көп салальы тәжірибе мен жергілікті емес білімі мигранттарды мүмкіндіктерге негізделген кәсіпкерлікке деген ұмтылыспен құамтамасыз етеді. Мигранттар мен жергілікті тұрвындардың кәсіпкерлік себептерінің сипаттамалары мен қозваушы күштерін сальстыратын жұмыс күшінің динамикасын зерттеу мәліметтеріне талдау жасалды. Сауалнама жүргізілді, онда жергілікті әріптестерімен сальстыру бойынша кәсіпкер-мигранттар арасында мүмкіндіктерге негізделген кәсіпкерлік қ̧ызметтің жовары таралганын көрсетеді.

Жүргізілген талдау мен сауалнама негізінде кеңістіктік ұтқырлық тәжірибесі мүмкіндіктерге негізделген бизнеске кіру ықтималдызын едәуір арттыратыны анықталды. Жергілікті кәсіпкерлерге фирманың эндогендік сипаты көбірек әсер етеді, ал мигрант кәсіпкерлер жергілікті қажеттіліктерге де, нарықтық аймақтармен сыртқы байланысқ̧а да негізделген бизнесті бастайды.

Түйінді сөздер: мигранттар; кеңістіктік ұтқырлық; кәсіпкерлік себептер; мүмкіндікке негізделген кәсіпкерлік; қажеттілікке негізделген кәсіпкерлік.

\section{SPATIAL MOBILITY OF THE WORKFORCE ORIENTED ON THE POSSIBILITY OF ENTREPRENEURSHIP DEVELOPMENT \\ *S.V.Bespalyy, L.I. Kashuk, A.R. Soltangazinov \\ Innovative University of Eurasia, Pavlodarc. \\ e-mail:sergeybesp@mail.ru}

Summary. The literature on regional entrepreneurship tends to neglect the interregional flows of human capital, and yet spatial mobility provides emerging entrepreneurs with knowledge and networks in different locations to exploit entrepreneurial opportunities. The aim of the study was to establish the relationship between mobility and entrepreneurship. It explored how multidisciplinary experience and non-local knowledge provide migrants with the desire for opportunity-based entrepreneurship. An analysis of the data from a survey of labor force dynamics is presented, which compares the characteristics and driving forces of entrepreneurial motives of migrants and local residents. A survey has been conducted that shows a higher prevalence of opportunity-based entrepreneurship among migrant entrepreneurs compared to their local counterparts.

Based on the analysis and survey conducted, it was found that the experience of spatial mobility significantly increases the likelihood of entering an opportunity-based business. Local entrepreneurs are more influenced by the endogenous nature of the firm, while migrant entrepreneurs start businesses based on both local needs and external linkages with wider market areas.

Key words: migrants; spatial mobility; entrepreneurial motives; opportunity-based entrepreneurship; necessity-based entrepreneurship. 